\title{
Б.Л. Рудник
}

Институт управления государственными ресурсами, НИУ ВШЭ, Москва

\section{B.В. Романова}

Центр государственного сектора экономики, Институт управления государственными ресурсами, НИУ ВШЭ, Центр межбюджетных отношений, НИФИ, Москва

\section{Бюджетное финансирование социально-культурной сферы}

\begin{abstract}
Аннотация. В статье излагаются результаты исследования показателей бюджетного финансирования социально-культурной сферы за период 20002015 гг. из средств консолидированного бюджета РФ, включая бюджеты государственных внебюджетных фондов, и федерального бюджета, относящиеся как к этой сфере в целом, так и ее отдельным отраслям. В целях проверки гипотезы о приоритетности для российского государства вопросов развития названной сферы в динамике анализируются показатели объемов ее государственного финансирования, а также доли направляемых в эту сферу бюджетных средств в общей сумме бюджетных расходов. Показатели бюджетного финансирования социально-культурной сферы в рассматриваемом периоде сопоставляются с аналогичными показателями стран, входящих в Организацию экономического сотрудничества и развития. Исследуются показатели, характеризующие бюджетные средства, направляемые на функционирование и развитие указанной сферы. Делаются выводы лишь о частичном подтверждении указанной гипотезы. В условиях жестких бюджетных ограничений подчеркивается актуальность задачи повышения эффективности бюджетных расходов. Анализируется реализация реформ, играющих ключевую роль в ее решении.
\end{abstract}

Ключевые слова: бюджетные средства, бюджетное финансирование; сочиально-культурная сфера, консолидированный бюджет РФ, федеральный бюджет, государственные (мунииипальные) услуги.

Классификация JEL: H51, H52, H53, H55.

\section{1. Введение}

В данной статье отражены наиболее значимые результаты исследования показателей расходов на социально-культурную сферу ${ }^{1}$ в 2000-2015 гг. из средств консолидированного бюджета РФ, включая бюджеты государственных внебюджетных фондов и федерального бюджета как относящихся к этой сфере в целом, так и ее отдельным отраслям ${ }^{2}$. Основной целью анализа финансовых показателей являлась проверка гипотезы о приоритетности для российского государства задач развития данной сферы, что, предположительно, нашло отражение в многократном увеличении объемов ее бюджетного финансирования ${ }^{3}$, росте доли направляемых в эту сферу бюджетных средств

\footnotetext{
1 Включает: образование, здравоохранение, культуру, социальную политику, физическую культуру и спорт, СМИ.

${ }^{2}$ В достаточно полном виде эти результаты представлены в книге (Ксынкина и др., 2016). Наряду с авторами данной статьи в исследовании приняли участие сотрудники Института управления государственными ресурсами НИУ ВШЭ Г.М. Ксынкина, А.В. Мацкевич, Е.А. Николаенко, Л.М. Ханова.

3 Отметим, что бюджетные поступления доминируют в объеме поступлений учреждений социально-культурной сферы, даже учреждений, ведущих активную платную деятельность. Так, для вузов они составляют порядка $2 / 3$, театров и концертных организаций $-3 / 4$ этого объема.
} 
в общей сумме бюджетных расходов и позволило России приблизиться по бюджетной обеспеченности социально-культурной сферы к уровню развитых зарубежных стран ${ }^{4}$. Причем на ситуацию принципиально не повлиял мировой финансовый кризис 2008-2010 гг.

Показатели бюджетного финансирования социально-культурной сферы в исследуемом периоде сопоставляются с аналогичными показателями стран, входящих в Организацию экономического сотрудничества и развития (далее - ОЭСР). Анализируются показатели, характеризующие объемы бюджетных средств, направляемых на функционирование и развитие этой сферы.

Следует особо отметить, что в рассматриваемом периоде в социально-культурной сфере был реализован ряд особо крупных проектов, направленных на ее развитие. Это прежде всего приоритетные национальные проекты «Здоровье» и «Образование».

В целях анализа рассматриваются:

- фактические показатели ${ }^{5}$, относящиеся к:

- 2000-2008 гг. (период восстановления и роста экономики России);

- 2011-2015 гг. (восстановление экономики России после мирового финансового кризиса, последние годы);

- прогнозные показатели консолидированного бюджета РФ в соответствии с проектом «Основные направления бюджетной политики на 2016 год и на плановый период 2017 и 2018 годов»;

- плановые показатели федерального бюджета на 2016 г. в соответствии с Федеральным законом от 14.12.2015 № 359-Ф3 «О федеральном бюджете на 2016 год».

На протяжении рассматриваемого периода бюджетная классификация Российской Федерации неоднократно пересматривалась. В связи с этим показатели бюджетных расходов были приведены в сопоставимый по годам формат ${ }^{6}$.

В научной литературе присутствуют работы, в которых в той или иной мере затрагиваются проблемы бюджетного финансирования отдельных отраслей социально-культурной сферы: (Абанкина и др., 2012) - образование, (Банин, 2012; Кулькова, 2014) - здраво-

\footnotetext{
${ }^{4}$ В случае справедливости данной гипотезы можно будет согласиться с упреком Минфина России в адрес российских отраслей социально-культурной сферы, суть которого состоит в том, что, несмотря на увеличение бюджетных расходов, Россия отстает по качеству государственных услуг от развитых зарубежных стран, причем разрыв не сокращается (доклад «Об основных направлениях повышения эффективности расходов федерального бюджета», опубликованный на сайте Минфина России (minfin.ru), дата обращения 24.03.2016).

5 Данные об исполнении расходов консолидированного бюджета Российской Федерации и федерального бюджета за период 2000-2014 гг. представлены на основании годовых отчетов об исполнении консолидированного бюджета Российской Федерации и бюджетов государственных внебюджетных фондов, а также отчетов об исполнении федерального бюджета на соответствующий год (www.roskazna.ru). Данные об исполнении расходов консолидированного бюджета РФ и федерального бюджета за 2015 г. представлены на основании ежемесячных отчетов об исполнении консолидированного бюджета РФ и бюджетов государственных внебюджетных фондов, а также отчетов об исполнении федерального бюджета за соответствующий год (www. roskazna.ru).

${ }^{6}$ В соответствии с бюджетной классификацией Российской Федерации, утвержденной Приказом Министерства финансов Российской Федерации от 01.07.2013 № 65н «Об утверждении Указаний о порядке применения бюджетной классификации Российской Федерации».
} 
охранение, (Музычук, Рубинштейн, 2014) - культура. В данной статье проводится анализ бюджетного финансирования этой сферы в целом с выделением составляющих ее отраслей.

\section{2. Время устойчивого роста}

Проведенный анализ показал многократное увеличение объема бюджетного финансирования социально-культурной сферы (табл. 1). В период 2000-2015 гг. расходы на эту сферу консолидированного бюджета РФ выросли в 18,1 раза в номинальном и в 3,0 раза в реальном выражении ${ }^{7}$.

В период 2000-2015 гг. по отдельным отраслям данной сферы имела место следующая динамика ${ }^{8}$ :

- образование - рост в номинальном выражении в 14,0 раз, в реальном - в 2,3 раза;

- здравоохранение - в 13,0 и 2,2 раза соответственно;

- культура - в 13,9 и 2,3 раза соответственно;

- социальная политика - в 22,8 и 3,8 раза соответственно.

Отмечая увеличение бюджетных расходов на социально-культурную сферу применительно к периоду 2000-2015 гг. в целом, следует

\section{Таблица 1}

Расходы консолидированного бюджета РФ на социально-культурную сферу, 2000-2015 гг.

\begin{tabular}{l|r|r|r|r|r|r|r|c}
\hline \multicolumn{1}{c|}{ Показатель } & \multicolumn{1}{c|}{2000} & \multicolumn{1}{c}{2005} & 2008 & 2011 & 2012 & 2013 & 2014 & 2015 \\
\hline \hline $\begin{array}{l}\text { Номинальное выра- } \\
\text { жение, млрд руб. }\end{array}$ & 922,9 & 3642,0 & 7287,3 & 11245,9 & 13215,2 & 14678,0 & 15154,2 & 16727,1 \\
\hline $\begin{array}{l}\text { Реальное выражение } \\
\text { (в условиях 2000 г.), } \\
\text { млрд руб. }\end{array}$ & 922,9 & 1656,2 & 2143,4 & 2450,2 & 2681,5 & 2831,4 & 2727,0 & 2797,6 \\
\hline В\% к ВВП & 12,7 & 16,9 & 17,7 & 20,1 & 21,3 & 22,2 & 21,2 & 22,8 \\
\hline $\begin{array}{l}\text { Доля расходов } \\
\text { в общих расходах, } \%\end{array}$ & 40,5 & 53,4 & 51,5 & 56,2 & 57,0 & 58,0 & 54,9 & 57,1 \\
\hline $\begin{array}{l}\text { Темп роста расхо- } \\
\text { дов (в номинальном } \\
\text { выражении), \% }\end{array}$ & - & 394,6 & 200,1 & 154,3 & 117,5 & 111,1 & 100,0 & 100,0 \\
\hline $\begin{array}{l}\text { Темп роста расходов } \\
\text { (в реальном выраже- } \\
\text { нии), \% }\end{array}$ & - & 179,5 & 129,4 & 114,3 & 109,4 & 105,6 & 103,2 & 110,4 \\
\hline $\begin{array}{l}\text { Справка: } \\
\text { объем ВвП }\end{array}$ & 7305,6 & 21609,8 & 41276,8 & 55967,2 & 62176,5 & 66190,1 & 71406,4 & 73515,0 \\
\hline $\begin{array}{l}\text { индекс-дефлятор } \\
\text { ВВП }\end{array}$ & 137,6 & 119,3 & 118,0 & 115,9 & 107,4 & 105,2 & 107,2 & 107,7 \\
\hline
\end{tabular}

Примечание. Данные по 2000 г. приведены в сопоставимом формате (с учетом государственных внебюджетных фондов); символ «-» означает отсутствие данных.

\footnotetext{
7 Отметим, что расходная часть консолидированного бюджета РФ включает расходы государственных внебюджетных фондов.

8 Уточним, что в проведенном исследовании детально анализировались показатели бюджетного финансирования четырех названных ниже отраслей, объем финансирования которых составляет более $97 \%$ расходов консолидированного бюджета РФ на социально-культурную сферу.
} 
выделить в этом периоде две его части: до и после 2013 г. До 2013 г. происходил устойчивый рост расходов на указанную сферу. Наиболее высокие темпы роста отмечаются в 2000-2005 гг., когда расходы увеличились в 3,9 раза в номинальном и в 1,8 раза в реальном выражении. Далее динамика существенно замедлилась. Так, за весь период 2005-2013 гг. рассматриваемые расходы увеличились в 4,0 раза в номинальном выражении и в 1,7 раза в реальном. При этом не наблюдается ускорение динамики в связи с реализацией приоритетных национальных проектов «Образование» и «Здравоохранение» как по соответствующим отраслям, так и по социально-культурной сфере в целом ${ }^{9}$. Отметим, что положительная динамика не была сломана мировым финансовым кризисом 2008-2010 гг.

В результате роста расходов на социально-культурную сферу бюджетная обеспеченность отраслей данной сферы заметно приблизилась к показателям развитых зарубежных стран ${ }^{10}$ (табл. 2), однако все еще далеко отстает от них. Как видно из этой таблицы, российские показатели вышли на уровень, сопоставимый с уровнем входящих в ОЭСР стран бывшего Восточного блока (за исключением здравоохранения, но и здесь прогресс очевиден).

До 2013 г. устойчиво росли расходы консолидированного бюджета РФ на социально-культурную сферу в процентах к ВВП (табл. 3). Если в 2000 г. они составляли 12,6\%, то в 2013 г. - 22,2\% ВВП, т.е. увеличились почти на 10 п.п. Рост данного показателя наблюдается по всем отраслям социально-культурной сферы. При этом его значения для социальной политики существенно выросли (почти в три раза).

В 2013 г. показатель доли расходов на социально-культурную сферу в общем объеме расходов консолидированного бюджета РФ достиг максимального значения за рассматриваемый период $(58,0 \%-$

таблица 2

Бюджетное финансирование социально-культурной сферы в расчете на одного жителя в России и странах, входящих в ОЭСР, \%

\begin{tabular}{l|c|c|c|c}
\hline \multicolumn{1}{c|}{ Показатель } & Образование & $\begin{array}{c}\text { Здравоохра- } \\
\text { нение }\end{array}$ & Культура & $\begin{array}{c}\text { Социальная } \\
\text { политика }\end{array}$ \\
\hline \hline & 2005 & 11 & $29^{*}$ & 10 \\
\hline РФ к средней по ОЭСР & 13 & 34 & $52^{*}$ & 31 \\
\hline $\begin{array}{l}\text { РФ к средней по входящим в ОЭСР } \\
\text { странам бывшего Восточного блока }\end{array}$ & 37 & 2013 & 35 & 28 \\
\hline \multicolumn{7}{|c|}{36} & 21 & 70 & 80 \\
\hline $\begin{array}{l}\text { РФ к средней по ОЭСР средней по входящим в ОЭСР } \\
\text { странам бывшего Восточного блока }\end{array}$ & 90 & 55 & & \\
\hline
\end{tabular}

Примечание. В таблице символом «*» обозначены значения за 2008 г.

Источник: база данных Eurostat в части расходов стран, входящих в ОЭСР.

\footnotetext{
${ }^{9}$ Применительно к высшему образованию на данный факт указано в работе (Абанкина и др., 2012 ).

${ }^{10}$ Рассматриваются страны, входящие в ОЭСР.
} 
см. табл. 1). В 2000 г. его значение составило 40,5\%, т.е. к 2013 г. оно увеличилось на 17,5 п.п. Фиксируя рост этой доли, отметим, что в отраслевом разрезе ситуация выглядит совсем не так однозначно (табл. 4). К 2013 г. доля расходов на образование выросла лишь на 1,9 п.п., на культуру - на 1 п.п., а на здравоохранение доля даже сократилась (на 0,4 п.п.).

Расходы на социально-культурную сферу росли высокими, но различными темпами по составляющим ее отраслям. Опережающие темпы роста расходов наблюдались в социальной политике. Заметно более низкие - в других отраслях. В связи с этим менялась структура бюджетных расходов на социально-культурную сферу (табл. 5). В результате она претерпела существенные изменения (рис. 1). В частности, если в 2000 г. расходы на образование составляли 23,4\% общего объема бюджетных расходов на данную сферу, то в 2015 г. уже $18,1 \%$, т.е. они сократились на 5,3 п.п.; расходы на социальную политику составляли соответственно $47,7 \%$ и 61,5 , т.е. они выросли на 13,8 п.п. Из данного факта можно сделать вывод, что в рассматриваемом периоде особо приоритетными для государства являлись расходы на социальную защиту населения, т.е. в определенном смысле состав-

Таблица 3

Динамика расходов консолидированного бюджета РФ в 2000-2015 гг. по отраслям социально-культурной сферы, \% к ВВП

\begin{tabular}{l|c|c|c|c|c|c|c|c}
\hline \multicolumn{1}{c|}{ Отрасль } & 2000 & 2005 & 2008 & 2011 & 2012 & 2013 & 2014 & 2015 \\
\hline \hline Социально-культурная сфера & 12,6 & 16,9 & 17,7 & 20,1 & 21,3 & 22,2 & 21,2 & 22,8 \\
\hline Образование & 3,0 & 3,7 & 4,0 & 4,0 & 4,1 & 4,4 & 4,3 & 4,1 \\
\hline Здравоохранение & 3,0 & 3,6 & 3,4 & 3,5 & 3,7 & 3,5 & 3,5 & 3,9 \\
\hline Культура & 0,4 & 0,5 & 0,6 & 0,6 & 0,5 & 0,6 & 0,6 & 0,5 \\
\hline Социальная политика & 6,0 & 8,7 & 9,1 & 11,6 & 12,4 & 13,2 & 12,3 & 13,7 \\
\hline Физическая культура и спорт & 0,1 & 0,1 & 0,3 & 0,3 & 0,3 & 0,3 & 0,4 & 0,3 \\
\hline СМИ & 0,2 & 0,2 & 0,1 & 0,2 & 0,2 & 0,2 & 0,2 & 0,2 \\
\hline
\end{tabular}

Таблица 4

Доля расходов консолидированного бюджета РФ в 2000-2015 гг. по отдельным отраслям социально-культурной сферы, \%

\begin{tabular}{|c|c|c|c|c|c|c|c|c|}
\hline Отрасль & 2000 & 2005 & 2008 & 2011 & 2012 & 2013 & 2014 & 2015 \\
\hline Образование & 9,5 & 11,8 & 11,8 & 11,2 & 11,0 & 11,4 & 11,0 & 10,4 \\
\hline Здравоохранение & 9,6 & 11,2 & 10,0 & 9,7 & 9,9 & 9,2 & 9,2 & 9,8 \\
\hline Социальная политика & 19,3 & 27,7 & 26,6 & 32,6 & 33,4 & 34,6 & 31,9 & 34,3 \\
\hline Культура & 1,3 & 1,7 & 1,8 & 1,6 & 1,5 & 1,5 & 1,5 & 1,8 \\
\hline
\end{tabular}


ляли расходы текущего характера. Что касается расходов на образование, играющего ключевую роль в развитии человеческого капитала, то они не занимали первых мест в числе социальных приоритетов государства.

Остановимся на финансировании социально-культурной сферы из средств федерального бюджета (табл. 6). В период 20002015 гг. расходы на эту сферу выросли в 22,5 раза в номинальном и в 3,7 раза в реальном выражениях ${ }^{11}$.

По отдельным отраслям данной сферы имела место следующая динамика: образование - рост в номинальном выражении в 14,9 раз, в реальном - в 2,5 раза; здравоохранение - в 27,8 и 4,7 раза соответственно; культура - в 14,0 и 2,3 раза соответственно; социальная политика - в 28,1 и 4,7 раза соответственно.

Расходы федерального бюджета на социально-культурную сферу в целом в отличие от расходов консолидированного бюджета

\section{Таблица 5}

Динамика структуры расходов консолидированного бюджета РФ в 2000-2015 гг. на социально-культурную сферу (СКС), \%

\begin{tabular}{l|r|r|r|r|r|r|r|r}
\hline \multicolumn{1}{c|}{ Отрасль } & 2000 & 2005 & 2008 & 2011 & 2012 & 2013 & 2014 & 2015 \\
\hline \hline Образование & 23,4 & 22,0 & 22,9 & 19,8 & 19,3 & 19,7 & 20,0 & 18,1 \\
\hline Культура & 3,1 & 3,2 & 3,4 & 2,8 & 2,6 & 2,6 & 2,7 & 2,4 \\
\hline Здравоохранение & 23,8 & 21,1 & 19,4 & 17,2 & 17,3 & 15,8 & 16,7 & 17,1 \\
\hline Социальная политика & 47,7 & 51,9 & 51,7 & 57,9 & 58,5 & 59,6 & 58,1 & 60,1 \\
\hline $\begin{array}{l}\text { Физическая культура } \\
\text { и спорт }\end{array}$ & 0,7 & 0,8 & 1,8 & 1,5 & 1,4 & 1,5 & 1,7 & 1,5 \\
\hline СМИ & 1,3 & 1,0 & 0,8 & 0,8 & 0,9 & 0,8 & 0,8 & 0,8 \\
\hline
\end{tabular}
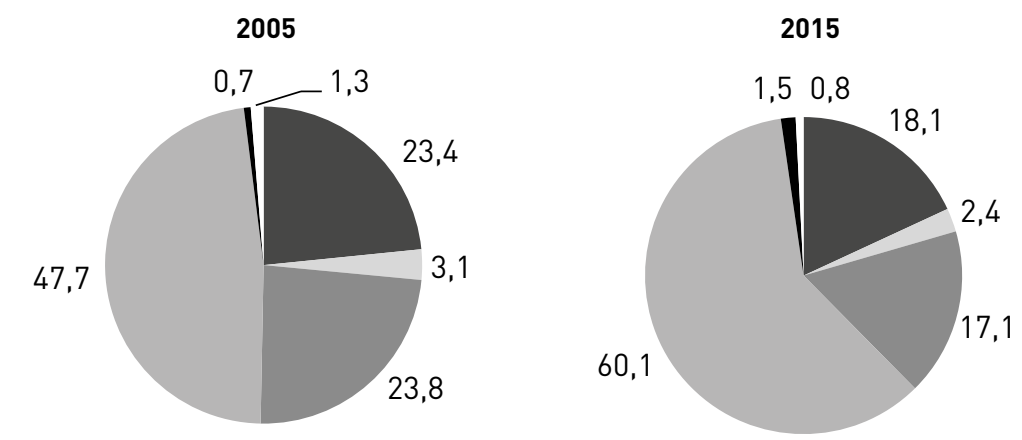

Образование

Здравоохранение

Физическая культура и спорт

Культура, кинематография

Социальная политика

Средства массовой информации

Рис. 1

Изменение структуры бюджетных расходов на сочиально-культурную сферу

\footnotetext{
11 Отметим, что расходная часть федерального бюджета не включает трансферты государственным внебюджетным фондам.
} 
Расходы федерального бюджета в 2000-2015 гг.

на социально-культурную сферу (без учета трансфертов государственным внебюджетным фондам), \%

\begin{tabular}{l|c|c|c|c|c|c|c|c|c}
\hline \multicolumn{1}{c|}{ Показатель } & 2000 & 2005 & 2008 & 2011 & 2012 & 2013 & 2014 & 2015 & $\begin{array}{c}2016 \\
\text { (план) }\end{array}$ \\
\hline $\begin{array}{l}\text { Номинальное выра- } \\
\text { жение, млрд руб. }\end{array}$ & 111,9 & 544,6 & 1257,0 & 1789,1 & 2207,1 & 2224,0 & 2354,2 & 2457,8 & 2515,0 \\
\hline $\begin{array}{l}\text { Реальное выражение } \\
\text { (в условиях 2000 г.) } \\
\text { млрд руб. }\end{array}$ & 111,9 & 247,6 & 369,7 & 389,8 & 447,6 & 429,4 & 424,0 & 411,1 & 389,1 \\
\hline В \% к ВвП & 1,5 & 2,5 & 3,0 & 3,2 & 3,5 & 3,4 & 3,3 & 3,3 & 3,2 \\
\hline $\begin{array}{l}\text { Доля расходов СКС } \\
\text { в общих расходах, \% }\end{array}$ & 10,9 & 15,5 & 16,6 & 16,4 & 17,1 & 16,7 & 16,2 & 15,7 & 15,5 \\
\hline $\begin{array}{l}\text { Темп роста расхо- } \\
\text { дов (в номинальном } \\
\text { выражении), \% }\end{array}$ & - & 486,6 & 230,8 & 142,3 & 123,4 & 100,8 & 105,9 & 104,4 & 102,3 \\
\hline $\begin{array}{l}\text { Темп роста расходов } \\
\text { в реальном выраже- } \\
\text { нии), \% }\end{array}$ & - & 221,3 & 149,3 & 105,4 & 114,8 & 95,9 & 98,7 & 97,0 & 94,7 \\
\hline
\end{tabular}

РФ устойчиво росли лишь до 2012 г. Наиболее высокие темпы роста указанных расходов отмечаются в 2000-2005 гг. (в номинальном выражении увеличение в 4,9 раза, в реальном - в 2,2 раза). В последующем динамика существенно замедлилась. Так, за весь период 2005-2012 гг. рассматриваемые расходы увеличились в 4,0 раза в номинальном выражении и в 1,7 раза в реальном. При этом на положительную динамику расходов принципиально не повлиял мировой финансовый кризис 2008-2010 гг.

В 2012 г. отмечается максимальное значение $(3,5 \%)$ за рассматриваемый период показателя объема расходов на социально-культурную сферу, выраженного в процентах к ВВП (табл. 7). В 2000 г. его значение составило 1,5\%, а к 2012 г. оно увеличилось на 2 п.п. Если посмотреть в отраслевом разрезе, то значительный рост наблюдается по всем отраслям социально-культурной сферы за исключением культуры, где значение данного показателя не изменилось.

О повышении значимости расходов на социально-культурную сферу свидетельствует увеличение удельного веса этих расходов в общем объеме расходов федерального бюджета (см. табл. 6). В 2012 г. указанный показатель достиг максимального значения за рассматриваемый период (17,1\%). С 2000 по 2012 г. его значение увеличилось на 6,2 п.п. В то же время в разрезе отраслей данной сферы динамика существенно отличалась (табл. 8). Наибольший рост значения этого показателя произошел в здравоохранении (более чем в 2 раза) в социальной политике (в 1,8 раза). Заметно меньшую динамику продемон- 
стрировала доля расходов на образование и почти не изменилась доля расходов на культуру.

В связи с существенными различиями в темпах роста бюджетных расходов по отраслям социально-культурной сферы менялась структура этих расходов на данную сферу (табл. 9). В результате она претерпела существенные изменения (рис. 2): в наибольшей степени (на 10,2 п.п.) вырос удельный вес расходов на социальную политику,

Таблица 7

Динамика расходов федерального бюджета в 2000-2015 гг. по отдельным отраслям социально-культурной сферы, \% к ВВП

\begin{tabular}{l|c|c|c|c|c|c|c|c|c}
\hline \multicolumn{1}{c|}{ Отрасль } & 2000 & 2005 & 2008 & 2011 & 2012 & 2013 & 2014 & 2015 & $\begin{array}{c}2016 \\
\text { (план) }\end{array}$ \\
\hline \hline Социально-культурная сфера & 1,5 & 2,5 & 3 & 3,2 & 3,5 & 3,4 & 3,3 & 3,3 & 3,2 \\
\hline Образование & 0,5 & 0,8 & 0,9 & 0,9 & 0,9 & 1 & 0,9 & 0,8 & 0,7 \\
\hline Здравоохранение & 0,2 & 0,4 & 0,8 & 0,8 & 0,9 & 0,7 & 0,7 & 0,7 & 0,6 \\
\hline Культура & 0,1 & 0,2 & 0,1 & 0,1 & 0,1 & 0,1 & 0,1 & 0,1 & 0,1 \\
\hline Социальная политика & 0,6 & 1,1 & 1 & 1,1 & 1,4 & 1,3 & 1,4 & 1,6 & 1,6 \\
\hline
\end{tabular}

таблица 8

Доля расходов федерального бюджета в 2000-2015 гг. по отдельным отраслям социально-культурной сферы, \%

\begin{tabular}{l|c|c|c|c|c|c|c|c|c}
\hline \multicolumn{1}{c|}{ Отрасль } & 2000 & 2005 & 2008 & 2011 & 2012 & 2013 & 2014 & 2015 & $\begin{array}{c}2016 \\
(\text { план })\end{array}$ \\
\hline \hline Образование & 3,8 & 4,6 & 5 & 4,9 & 4,5 & 4,8 & 4,2 & 3,8 & 3,5 \\
\hline Здравоохранение & 1,7 & 2,4 & 4,4 & 4,3 & 4,3 & 3,5 & 3,4 & 3,1 & 2,8 \\
\hline Культура & 0,6 & 1 & 0,8 & 0,8 & 0,7 & 0,7 & 0,7 & 0,6 & 0,6 \\
\hline Социальная политика & 4 & 6,8 & 5,6 & 5,5 & 6,7 & 6,6 & 6,9 & 7,3 & 7,7 \\
\hline
\end{tabular}

таблица 9

Динамика структуры расходов федерального бюджета в 2000-2015 гг. на социально-культурную сферу, \%

\begin{tabular}{l|c|c|c|c|c|c|c|c|c}
\hline \multicolumn{1}{c|}{ Отрасль } & 2000 & 2005 & 2008 & 2011 & 2012 & 2013 & 2014 & 2015 & $\begin{array}{c}2016 \\
\text { (план) }\end{array}$ \\
\hline $\begin{array}{l}\text { Образование - в общих расходах } \\
\text { на СКС }\end{array}$ & 35,4 & 29,9 & 30,3 & 29,7 & 26,5 & 29,1 & 26,0 & 24,0 & 22,4 \\
\hline $\begin{array}{l}\text { Здравоохранение - в общих } \\
\text { расходах на СКС }\end{array}$ & 15,4 & 15,7 & 26,3 & 26,1 & 24,9 & 20,8 & 20,9 & 19,5 & 18,1 \\
\hline $\begin{array}{l}\text { Культура - в общих расходах } \\
\text { на СКС }\end{array}$ & 4,8 & 6,2 & 4,8 & 4,6 & 4,0 & 4,2 & 4,1 & 3,6 & 3,9 \\
\hline $\begin{array}{l}\text { Социальная политика - в общих } \\
\text { расходах на СКС }\end{array}$ & 36,4 & 43,9 & 34,0 & 33,7 & 39,0 & 39,4 & 42,7 & 46,6 & 49,5 \\
\hline
\end{tabular}



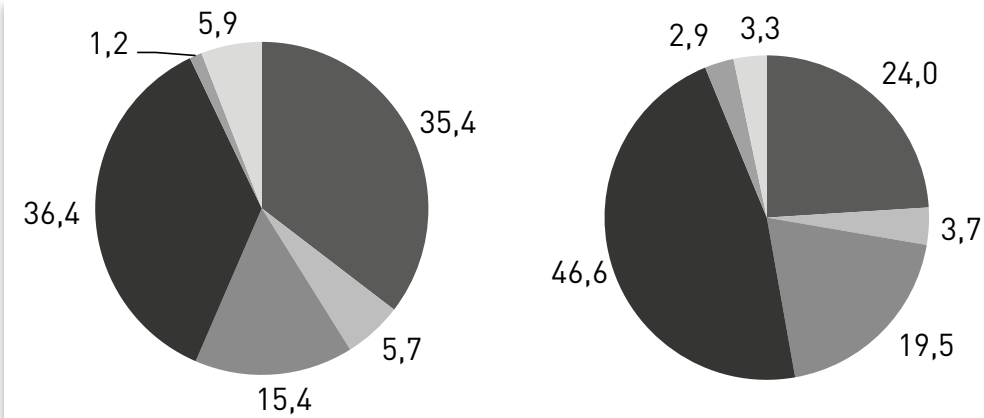

Образование

Здравоохранение

Физическая культура и спорт

Культура, кинематография

Социальная политика

Средства массовой информации

Puc. 2

Изменение структуры бюджетных расходов федерального бюджета на сочиально-культурную сферу

произошел рост (на 4,1 п.п.) доли расходов на здравоохранение. В то же время сократились удельные веса расходов на образование и культуру (соответственно на 11,4 и 1,2 пп), т.е. и в данном случае вопросы социальной защиты пользовались явным приоритетом государства.

\section{3. Угроза изменения позитивной тенденции}

В последние годы возникла реальная угроза изменения многолетней позитивной тенденции. В 2014 г. по сравнению с 2013 г. бюджетные расходы на социально-культурную сферу в реальном выражении сократились на $3,7 \%$, также как и в процентах к ВВП - на 1 п.п. (см. табл. 1). В разрезе отраслей (табл. 10) снижение показателей произошло в образовании и социальной политике. По отрасли «Культура» указанные показатели остались практически на уровне 2013 г. Произошло замедление темпов роста расходов на социально-культурную сферу в номинальном выражении.

В 2014 г. расходы на социально-культурную сферу росли меньшими темпами, чем общий объем расходов консолидированного бюджета РФ. Так, показатель темпа роста расходов на социальнокультурную сферу в реальном выражении составляет $96,3 \%$, а темп роста расходов названного бюджета $-101,9 \%$. В результате доля этой сферы в общих расходах консолидированного бюджета РФ уменьшилась на 3,2 п.п. Показатели по отдельным отраслям представлены в табл. 4.

В 2015 г. расходы на социально-культурную сферу в реальном выражении сохранились на уровне 2014 г. Однако в разрезе отраслей сокращение расходов в реальном выражении отмечено по всем отраслям социально-культурной сферы, кроме здравоохранения и социальной политики (табл. 11). В то же время в образовании и культуре расходы сократились не только в реальном, но и в номинальном выражении. Снизилась и их доля как в общем объеме расходов на соци- 
ально-культурную сферу, так и в общем объеме расходов консолидированного бюджета РФ.

Таблица 10

Расходы консолидированного бюджета РФ в 2013-2015 гг. по отдельным отраслям социально-культурной сферы

\begin{tabular}{l|l|r|r|r}
\hline \multicolumn{1}{c|}{ Отрасль } & \multicolumn{1}{|c|}{ Расходы } & 2013 & \multicolumn{1}{c}{2014} & 2015 \\
\hline \hline \multirow{5}{*}{ Образование } & Расходы в номинальном выражении, млрд руб. & 2888,8 & 3037,3 & 3034,6 \\
\cline { 2 - 5 } & Расходы в реальном выражении, млрд руб. & 557,7 & 547,0 & 507,5 \\
\cline { 2 - 5 } & В \% к ВВП & 4,4 & 4,3 & 4,1 \\
\hline \multirow{5}{*}{ Здравоохранение } & Расходы в номинальном выражении, млрд руб. & 2318,0 & 2532,7 & 2861,0 \\
\cline { 2 - 5 } & Расходы в реальном выражении, млрд руб. & 447,5 & 456,1 & 478,5 \\
\cline { 2 - 5 } & В \% к ВВП & 3,5 & 3,5 & 3,9 \\
\hline \multirow{5}{*}{ Культура } & Расходы в номинальном выражении, млрд руб. & 377,0 & 410,0 & 395,6 \\
\cline { 2 - 5 } & Расходы в реальном выражении, млрд руб. & 72,8 & 73,8 & 66,2 \\
\cline { 2 - 5 } & В \% к ВВП & 0,6 & 0,6 & 0,5 \\
\hline \multirow{2}{*}{\begin{tabular}{l} 
поциальная \\
\cline { 2 - 5 }
\end{tabular}} & Расходы в номинальном выражении, млрд руб. & 8757,2 & 8803,3 & 10055,4 \\
\cline { 2 - 5 } & Расходы в реальном выражении, млрд руб. & 1690,6 & 1585,5 & 1681,8 \\
\cline { 2 - 5 } & В \% к ВВП & 13,2 & 12,3 & 13,7 \\
\hline
\end{tabular}

\section{Таблица 11}

Расходы федерального бюджета в 2013-2015 гг. по отдельным отраслям социально-культурной сферы

\begin{tabular}{|c|c|c|c|c|}
\hline Отрасль & Расходы & 2013 & 2014 & 2015 \\
\hline \multirow{3}{*}{ Образование } & Расходы в номинальном выражении, млрд руб. & 646,9 & 611,9 & 579,4 \\
\hline & Расходы в реальном выражении, млрд руб. & 124,8 & 110,1 & 96,8 \\
\hline & В \% к ВВП & 1,0 & 0,9 & 0,8 \\
\hline \multirow{3}{*}{ Здравоохранение } & Расходы в номинальном выражении, млрд руб. & 462,2 & 493,1 & 347,9 \\
\hline & Расходы в реальном выражении, млрд руб. & 89,1 & 88,7 & 58,1 \\
\hline & В \% к ВВП & 0,7 & 0,7 & 0,7 \\
\hline \multirow{3}{*}{ Культура } & Расходы в номинальном выражении, млрд руб. & 94,7 & 97,8 & 90,7 \\
\hline & Расходы в реальном выражении, млрд руб. & 18,3 & 17,6 & 15,2 \\
\hline & В \% к ВВП & 0,1 & 0,1 & 0,1 \\
\hline \multirow{3}{*}{$\begin{array}{l}\text { Социальная } \\
\text { политика }\end{array}$} & Расходы в номинальном выражении, млрд руб. & 875,4 & 1006,2 & 1193,4 \\
\hline & Расходы в реальном выражении, млрд руб. & 168,9 & 181,1 & 199,4 \\
\hline & В \% к ВВП & 1,3 & 1,4 & 1,6 \\
\hline
\end{tabular}


Ухудшение экономической ситуации заметно сказалось на финансировании социально-культурной сферы из федерального бюджета. В 2014 г. по сравнению с 2013 г. бюджетные расходы в реальном выражении сократились на 1,3\%. Сокращение коснулось всех отраслей данной сферы, за исключением социальной политики (см. табл. 11). В наибольшей степени уменьшились расходы на образование. Они снизились не только в реальном, но и в номинальном выражении.

Расходы на социально-культурную сферу росли более низкими темпами, чем расходы федерального бюджета в целом (105,9 и 108,6\% соответственно). В итоге снизилась их доля в общем объеме бюджетных расходов (на 0,5 п.п.).

В 2015 г. по сравнению с 2014 г. положение еще более ухудшилось. Сократились номинальные расходы на образование $(3,5 \%)$, культуру $(8,2 \%)$, здравоохранение $(2,9 \%)$. Доля расходов на социальнокультурную сферу в общем объеме расходов федерального бюджета уменьшилась на 0,5 п.п.

В перспективе ситуация может ухудшиться. В Федеральном законе «О федеральном бюджете на 2016 год» в 2016 г. по сравнению с 2015 г. предусмотрено сокращение расходов федерального бюджета на социально-культурную сферу в реальном выражении (в ценах 2000 года) на 21,9 млрд руб., или на 5,3\%. Сокращение коснется почти всех отраслей социально-культурной сферы, исключая культуру и социальную политику. В то же время расходы на культуры упали ниже уровня 2005 г. еще в 2015 г. При этом в 2016 г. по сравнению с предыдущим годом планируется их незначительное повышение (на $0,8 \%$ ), однако они так и останутся ниже уровня 2005 г.

Особо обратим внимание на запланированное в 2016 г. снижение расходов федерального бюджета не только в реальном выражении, но и в номинальном выражении по следующим отраслям социальнокультурной сферы: образование - на 4,4\%, здравоохранение - на $5,1 \%$, физическая культура - на $0,9 \%$ и СМИ - на 2,0\%.

Также отметим, что в указанном законе в 2016 г. предусмотрено сокращение по сравнению с 2015 г. расходов на социально-культурную сферу в процентах к объему ВВП на 0,1 п.п., а также снижение их доли в общем объеме расходов федерального бюджета на 0,2 п.п. В связи с этим можно сделать вывод о снижении значимости расходов на социально-культурную сферу.

Особенно страдают расходы на развитие отраслей социальнокультурной сферы. Анализ структуры расходов на социально-культурную сферу в разрезе средств, направляемых на развитие и функционирование за период 2000-2016 гг., приведен на рис. 3. Начиная с 2012 г. прослеживается устойчивая тенденция сокращения средств на развитие в абсолютном выражении. В 2016 г. по сравнению с 2012 г. расходы на развитие сократились на $33 \%$. Также сократилась и их доля в общих расходах социально-культурной сферы (на 9,3 п.п). Данное 
сокращение прежде всего объясняется снижением объемов финансирования федеральных целевых программ, а также увеличением расходов на функционирование учреждений социально-культурной сферы, произведенным согласно Указу Президента от 07.05.2012 г. № 597 «О мероприятиях по реализации государственной социальной политики».

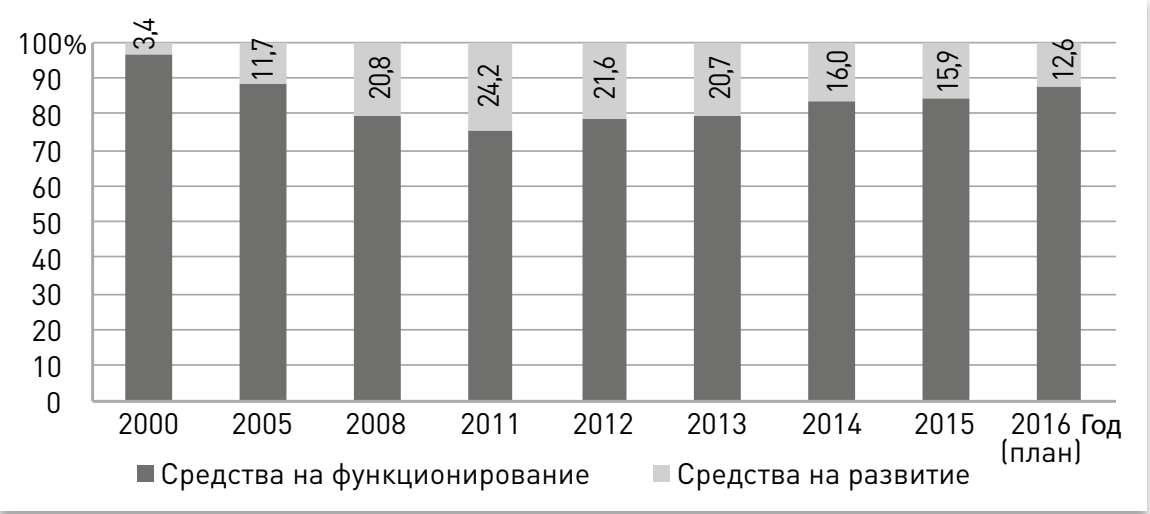

Pис. 3

Расходы федерального бюджета на сочиально-культурную сферу в разрезе средств, направляемых на развитие и функиионирование

\section{4. Выводы}

По результатам анализа можно сделать вывод, что выдвинутая выше гипотеза подтвердилась лишь частично.

С одной стороны, социально-культурная сфера в целом являлась для государства очевидным приоритетом, что выразилось в многократном увеличении объема ее бюджетного финансирования и росте удельного веса расходов на данную сферу в общем объеме бюджетных расходов в 1,4 раза $^{12}$. Российский показатель бюджетной обеспеченности вышел к 2013 г. на уровень, сопоставимый с уровнем входящих в ОЭСР стран бывшего Восточного блока. Многократно возросли расходы на социально-культурную сферу из средств федерального бюджета, почти в 1,5 раза увеличилась доля расходов на данную сферу в общем объеме бюджетных расходов. При этом заметно выросла доля расходов, направляемых на ее развитие: с 3,4\% в 2000 г. до 12,6\% в 2015 г. Позитивная динамика не была в целом нарушена мировым финансовым кризисом 2008-2010 гг.

С другой стороны, не столь оптимистичной выглядит ситуация по отдельным отраслям социально-культурной сферы. Так, доля расходов консолидированного бюджета РФ на образование и здравоохранение сократилась в 2015 г. по сравнению с 2000 г. соответственно на 0,9 и 0,2 п.п. Доля расходов федерального бюджета на образование и культуру осталась на том же уровне $(3,8 \%$ и $0,6 \%$ соответственно). Россия

\footnotetext{
12 В 2015 г. доля расходов на социально-культурную сферу в целом составила более половины $(57,1 \%)$ расходов в общем объеме консолидированного бюджета РФ.
} 
существенно отстает по бюджетной обеспеченности социально-культурной сферы от развитых зарубежных стран.

В последние годы возникла угроза изменения многолетней положительной тенденции. Так, в 2014-2015 гг. по отдельным отраслям социально-культурной сферы наблюдалось сокращение не только реальных, но и номинальных бюджетных расходов. Происходило снижение доли расходов на эту сферу в общем объеме бюджетных расходов.

Разумеется, наметившуюся тенденцию сокращения бюджетного финансирования социально-культурной сферы необходимо преодолеть. Россия должна достичь уровня, сопоставимого с уровнем развитых зарубежных стран. Вместе с тем в условиях жестких бюджетных ограничений особую актуальность приобретает такой источник финансирования, как повышение әффективности использования бюджетных средств. В последние годы государство реализует ряд мер, призванных обеспечить более полное задействование этого источника. Центральное место в их ряду занимают меры, направленные на дальнейшее развитие таких реформ, как внедрение инструментов программно-целевого управления и реформа государственных и муниципальных учреждений ${ }^{13}$.

Сегодня эти реформы, по сути, зашли в тупик. Так, в качестве недостатков принятых сегодня государственных программ называются: ${ }^{14}$

1) отсутствие полноценной система стратегических документов, задающих приоритеты государственной политики в сферах реализации государственных программ, т.е. ставится под сомнение обоснованность их целей;

2) показатели государственных программ не позволяют реально оценить достижение запланированных результатов, т.е. реализацию целей этих программ;

3) ненадлежащим образом определены сферы реализации отдельных государственных программ: присутствуют подпрограммы, не работающие на их цели, подпрограммы и ФЦП дублируют друг друга, т.е. отсутствует необходимая строгая привязка мероприятий к целям государственных программ.

Но при двух последних недостатках (подчеркнем, что они указаны Минфином России) государственные программы утрачивают характер инструментов целевого управления.

О неудаче реформы учреждений ${ }^{15}$ свидетельствуют произошедшие в последние годы отступления от ее ключевых идей, что выражается прежде всего в радикальном снижении уровня экономиче-

${ }^{13}$ Правовой базой этой реформы является Федеральный закон от 08.05.2010 № 83-ФЗ «О внесении изменений в отдельные законодательные акты Российской Федерации в связи с совершенствованием правового положения государственных (муниципальных) учреждений».

14 Подготовленный в 2015 г. доклад Минфина России «Об основных направлениях повышения эффективности расходов федерального бюджета». Опубликован на официальном сайте Минфина России (minfin.ru).

15 Причины проведения, цели, содержание, основные этапы и проблемы этой реформы подробно анализируются в работе (Лисин, Рудник, 2012). 
ской самостоятельности автономных учреждений (АУ) в прошедшие после принятия Федерального закона «Об автономных учреждениях» годы ${ }^{16}$. С тех пор АУ утратили самостоятельность в планировании своей финансово-хозяйственной деятельности, проведении закупок ${ }^{17}$. Существенно возрос объем предоставляемой ими отчетности. Также следует отметить, что если согласно первой редакции названного закона АУ могли размещать все свои средства на счетах, открытых им в кредитных организациях, то сегодня часть их средств (субсидии на осуществление капитальных вложений и приобретение объектов недвижимого имущества) в обязательном порядке размещается на лицевых счетах в органах Федерального казначейства, финансовых органах субъектов РФ, муниципальных образований.

Показателем кризиса реформы учреждений являются действия по дальнейшей централизации принятия решений по соответствующим вопросам, сосредоточение их в федеральном центре. Именно такой подход демонстрируется в отношении перечней государственных и муниципальных услуг, а также нормативов финансовых затрат.

Согласно части 3.1 статьи 69.2 БК РФ перечни государственных (муниципальных) услуг и работ формируются и ведутся на федеральном, региональном и местном уровнях в соответствии с базовыми (отраслевыми) перечнями государственных и муниципальных услуг и работ, утвержденными ФОИВ, осуществляющими функции по выработке государственной политики и нормативно-правовому регулированию в установленных сферах деятельности ${ }^{18}$. Иными словами, без разрешения федерального центра ни регионы, ни муниципалитеты не смогут обновлять состав услуг, оказывать населению услуги, соответствующие национально-культурным особенностям их жителей или дополнительно принятым перед ними обязательствам. Вряд ли в этом случае можно говорить о повышении эффективности бюджетных расходов.

В упоминавшийся Федеральный закон № 252-ФЗ в БК РФ также внесены изменения, касающиеся финансовых нормативов. С учетом этих изменений «объем финансового обеспечения выполнения государственного (муниципального) задания рассчитывается на основании нормативных затрат на оказание государственных (муниципальных) услуг.. с соблюдением общих требований, определенных ФОИВ, осуществляющими функции по выработке государственной политики и нормативно-правовому регулированию в установленных сферах деятельности» (часть четвертая статьи 69.2 БК РФ). Но представляется, что при столь широком разнообразии объективных условий деятельности учреждений различных российских регионов разработанные «общие требования» либо в силу их чрезвычайной общности окажутся бессодержательными, либо приведут к неоправданным усреднениям

\footnotetext{
16 Федеральный закон от 03.11.2006 № 174-Ф3 «Об автономных учреждениях».

${ }^{17}$ С 1 января 2012 г. закупочная деятельность АУ регулируется Федеральным законом от 18.07.2011 № 223-Ф3 «О закупках товаров, работ, услуг отдельными видами юридических лиц».

18 Данная норма введена в БК РФ Федеральным законом от 23.07.2013 № 252-Ф3 и действует с 01.01.2016.
} 
и, как следствие, отрицательно скажутся на качестве и эффективности предоставления государственных и муниципальных услуг.

Говоря о кризисе названных реформ, важно отметить, что они являются очередной попыткой неудавшихся преобразований, имеющих сходные цели и способы их реализации. Так, начиная с середины 1990-х годов последовательно внедрялись (Афанасьев, Шаш, 2014) следующие программы:

1) социально-экономического развития Российской Федерации,

2) федеральные целевые,

3) ведомственные целевые,

4) государственные.

Реформа учреждений должна рассматриваться, с одной стороны, как сегодняшний этап, а с другой - как важнейшая составная часть двух более ранних этапов трансформации организационно-экономических механизмов оказания государственных и муниципальных услуг, относящихся к концу 1980 - началу 1990-х годов. Целью этих трансформаций являлось достижение рационального баланса между свободой инициативы производителей таких услуг и государственным контролем их деятельности (табл. 12).

Основные задачи:

1) расширение экономических прав организаций,

2) повышение обоснованности объемов выделяемых государственным и муниципальным учреждениям бюджетных средств, прежде всего на основе внедрения нормативного подхода,

3) развитие альтернативных государственному источников финансирования социально-культурной сферы.

Попытки решения этих задач не приводили к успеху, и организационно-экономические механизмы социально-культурной сферы в основном оказывались в исходном положении, т.е. происходило не последовательное продвижение в намеченном направлении, а как бы движение по кругу.

Предшествующие неудачи позволяют предположить, что скромность результатов сегодняшних реформ обусловлена не столько недочетами в их проведении, сколько фундаментальными недостатками проводившейся череды крупных управленческих преобразований. При этом следует отметить, что неудачи преобразований на каждом их этапе не становились объектом критического научного осмысления.

Сегодня обозначились контуры следующего этапа трансформации организационно-экономических механизмов оказания государственных и муниципальных услуг, сутью которых является внедрение конкурентных принципов выбора поставщиков таких услуг и, соответственно, выделения бюджетных средств. В качестве основных составляющих данного этапа предлагаются ${ }^{19}$ :

1) рыночное размещение государственного (муниципального) заказа с участием частных организаций;

19 Доклад «Об основных направлениях повышения эффективности расходов федерального бюджета», опубликованный на сайте Минфина России (minfin.ru), дата обращения 24.03.2016 г. 
2) предоставление потребителям возможности самостоятельного выбора поставщика (с использованием сертификатов), разработка перечня услуг, которые можно получить по сертификатам;

3) принятие федерального закона «Об оказании государственных и муниципальных услуг на конкурентной основе»;

4) преобразование автономных и части бюджетных учреждений в государственные (муниципальные) автономные некоммерческие организации (ГМАНО).

Однако на сегодняшний день указанные составляющие еще недостаточно проработаны в концептуальном плане. Так, в докладе

Таблица 2

Этапы трансформации организационно-экономических механизмов оказания государственных и муниципальных услуг

\begin{tabular}{|c|c|c|}
\hline Этап & Новация & Реализация \\
\hline 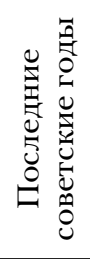 & $\begin{array}{l}\text { Внедрялся новый хозяйственный механизм } \\
\text { в отраслях социальной сферы. } \\
\text { 1. Повышение экономической самостоятельности } \\
\text { организаций (повышение экономической само- } \\
\text { стоятельности государственных учреждений). } \\
\text { 2. Бюджетное финансирование (внедрение } \\
\text { финансовых нормативов) }\end{array}$ & $\begin{array}{l}\text { На этот механизм успела перей- } \\
\text { ти лишь часть учреждений, нор- } \\
\text { мативы не были внедрены }\end{array}$ \\
\hline \multirow{5}{*}{ 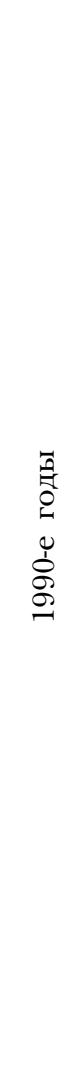 } & $\begin{array}{l}\text { Переход экономики России на рыночные условия } \\
\text { хозяйствования. } \\
1 . \text { Повышение экономической самостоятельности } \\
\text { организаций }\end{array}$ & \\
\hline & $\begin{array}{l}\text { 1.1. Развитие частного сектора (возможность при- } \\
\text { ватизации, льготы по налогу на прибыль частным } \\
\text { организациям, их бюджетное финансирование) }\end{array}$ & $\begin{array}{l}\text { 1.1. Приватизация в основном } \\
\text { не состоялась, налоговые льготы } \\
\text { в конце периода были отме- } \\
\text { нены, заметного финансирова- } \\
\text { ния не было }\end{array}$ \\
\hline & $\begin{array}{l}\text { 1.2. Широчайшая самостоятельность государ- } \\
\text { ственных учреждений }\end{array}$ & $\begin{array}{l}\text { 1.2. С началом 2000-х годов про- } \\
\text { изошло отступление: } \\
\text { а) перевод средств учреждений, } \\
\text { полученных из внебюджетных } \\
\text { источников, в органы казначей- } \\
\text { ства, контроль их расходования; } \\
\text { б) запрет на пользование } \\
\text { кредитом; } \\
\text { в) существенное ограничение } \\
\text { видов приносящей доходы } \\
\text { деятельности; } \\
\text { г) регулирование закупочной } \\
\text { деятельности специальным зако- } \\
\text { ном (o. 94-Ф3) }\end{array}$ \\
\hline & $\begin{array}{l}\text { 2. Бюджетное финансирование (внедрение } \\
\text { нормативов) }\end{array}$ & 2. Не внедрены \\
\hline & $\begin{array}{l}\text { 3. Развитие альтернативных (государственным) } \\
\text { источников финансирования: налоговые льготы } \\
\text { благотворителям }\end{array}$ & $\begin{array}{l}\text { 3. Отменены для благотворите- } \\
\text { лей - юридических лиц (в } 1995 \text { г. } \\
\text { частично, в } 2000 \text { г. полностью) }\end{array}$ \\
\hline
\end{tabular}


Окончание таблицы 2

\begin{tabular}{|c|c|c|}
\hline Әтап & Новация & Реализация \\
\hline \multirow{4}{*}{ 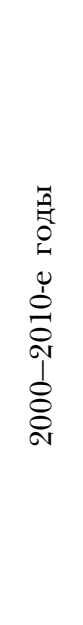 } & $\begin{array}{l}\text { Проводится реформа учреждений. } \\
\text { 1. Повышение экономической самостоятельности } \\
\text { организаций }\end{array}$ & \\
\hline & $\begin{array}{l}\text { 1.1. Развитие частного сектора (правовые основы } \\
\text { некоммерческой приватизации) }\end{array}$ & 1.1. Создать не удалось \\
\hline & $\begin{array}{l}\text { 1.2. Введены новые типы учреждений с высоким } \\
\text { уровнем экономической самостоятельности }\end{array}$ & $\begin{array}{l}\text { 1.2. С начала } 2010 \text {-х годов про- } \\
\text { исходит отступление: часть } \\
\text { средств АУ возвращена в казна- } \\
\text { чейство; ограничения на само- } \\
\text { стоятельное формирование } \\
\text { плана финансово-хозяйственной } \\
\text { деятельности; рост отчетности; } \\
\text { ограничение самостоятельности } \\
\text { в закупках (№ 223-Ф3) }\end{array}$ \\
\hline & $\begin{array}{l}\text { 2. Бюджетное финансирование: внедрение } \\
\text { нормативов }\end{array}$ & $\begin{array}{l}\text { 2. Процесс внедрения в полной } \\
\text { мере не завершен }\end{array}$ \\
\hline
\end{tabular}

Минфина России отсутствует определение понятия «государственный (муниципальный) заказ», не рассмотрены особенности механизмов его размещения, не обоснована необходимость принятия названного федерального закона в условиях, когда в отдельных отраслях уже используются конкурентные способы выбора поставщиков государственных (муниципальных) услуг. Возникают вопросы и к ГМАНО: автономная некоммерческая организация - форма частной, но не государственной или муниципальной организации.

Вместе с тем общее направление будущих преобразований представляется верным. Движения по кругу вряд ли удастся избежать, если пытаться сохранить неприкосновенность государственного сектора и все преобразования сосредоточить на отладке организационноэкономических условий функционирования составляющих его учреждений. Представляется, что важнейшими направлениями будущих реформ и должны стать некоммерческая приватизация части государственных учреждений, перевод их в статус НКО (возможно, с государственным участием), а также развитие конкурентных механизмов предоставления бюджетных средств на оказание государственных (муниципальных) услуг.

Однако прежде чем переходить к новому этапу трансформаций, представляется необходимым вернуть реформу учреждений в русло ее ключевых идей. Одной из таких, по сути забытых, идей, о чем было указано выше, является обеспечение высокого уровня экономической самостоятельности АУ. Именно учреждения этого типа предназначены для деятельности в условиях развитых конкурентных отношений, в них работают наиболее квалифицированные управленческие команды, в них проходит обкатку такая форма независимого 
контроля, как наблюдательный совет, они должны являться ориентиром для многих учреждений, которые сегодня в силу инерции или недостаточной подготовленности управленческих кадров оказались в статусе бюджетных учреждений.

\section{ЛИТЕРАТУРА}

Абанкина И.А., Абанкина Т.В., Филатова Л.М., Николаенко Е.А. (2012). Тенденции изменения общественного спроса на высшее образование в современной России / / Вопросы образования. № 3. С. 88-112.

Афанасьев М.П., Шаш Н.Н. (2014). Российские бюджетные реформы: от программ социально-экономического развития до государственных программ Российской Федерации // Вопросы государственного и мунииипального управления. № 2. С. 48-64.

Банин С.А. (2012). Здравоохранение России: вопросы финансирования и пути решения // Вестник Томского государственного университета. № 3. C. $112-117$.

Ксынкина Г.М., Николаенко Е.А., Романова В.В., Рудник Б.Л., Ханова Л.М. (2016). Анализ бюджетного финансирования социально-культурной сферы. М.: Изд. дом ГУ ВШЭ.

Кулькова В.Ю. (2014). Государственные расходы на здравоохранение: потенциал и методика сравнительного анализа // Финансовый журнал. № 3 (21). C. 35-46.

Лисин Н.В., Рудник Б.Л. (2012). Реформа бюджетного сектора: проблемы, риски и перспективы / / Вопросы государственного и мунииипального управления. № 2. С. 60-77.

Музычук В.Ю., Рубинштейн А.Я. (2014) Оптимизация или деградация? Между прошлым и будущим российской культуры / / Общественные науки и современность. № 6. С. 5-22.

Поступила в редакиию 5 сентября 2016 года

\section{REFERENCES (with English translation or transliteration)}

Abankina I., Abankina T., Filatova L., Nikolaenko E. (2012). Changing Trends in Public Demand for Higher Education in Modern Russia. Educational Studies, 3, 88-112 (in Russian).

Afanasyev M., Shash N. (2014). Russian Budgetary Reforms: from Programs of Social and Economic Development to State Programs of the Russian Federation. Public Administration Issues, 2, 48-64 (in Russian).

Banin S. (2012). Health Russia: Funding Issues and Solutions. Bulletin of the Tomsk State University, 3, 112-117 (in Russian).

Csinchina G., Nikolaenko E., Romanova V., Rudnik B., Hanova M. (2016). Analysis of the Budgetary Financing of Socio-Cultural Sphere. Moscow: Izd. dom Vysshey shkoly ekonomiki (in Russian).

Kulkova V. (2014). Public Expenditure on Health: Potential and Methodology of 
Comparative Analysis. Financial Journal, 3 (21), 35-46 (in Russian).

Lisin N., Rudnik B. (2012). Public Sector Reform: Problems, Risks and Perspectives. Public Administration Issues, 2, 60-77 (in Russian).

Muzichuk V., Rubinshtein A. (2014). Optimization or Degradation? Between the Past and the Future of Russian Culture. Obshchestvennye Nauki i Sovremennost', $6,5-22$ (in Russian).

Received 5.09.2016

\title{
B.L. Rudnik
}

Institute of Public Resource Management, National Research University Higher School of Economics, Moscow, Russia

\section{V.V. Romanova}

Center of Public Economy Sector, Institute of Public Resource

Management, National Research University Higher School of Economics, Senior Researcher of the Center of inter-budget relations, Scientificresearch financial Institute, Moscow, Russia

\section{The Budgetary Financing of Socio-Cultural Sphere}

\begin{abstract}
The article presents the study results of data on budgetary financing of socio-cultural sphere, including its individual sectors, for the period from 2000 to 2015, from the funds of the consolidated budget of the Russian Federation and the Federal budget. In order to test the hypothesis that Russian Government's priority is the development of the socio-cultural sphere in the dynamics the article analyzes the indicators of public funding volumes, as well as the shares allocated to this sector from the budget funds in the total budget expenditures. Indicators of the socio-cultural sphere budgetary financing during indicated period are compared with similar indicators of the countries belonging to the Organization for economic cooperation and development. The article examines indicators of budgetary funds allocated for functioning and development of the sphere. Conclusions are made about a partial confirmation of the mentioned hypothesis. Under the conditions of hard budget restrictions the urgency of the task to increase an efficiency of budgetary expenses is being emphasized. The article analyzes the implementation of reforms that play a key role in completing this task.
\end{abstract}

Keywords: budget funds, budgetary financing, socio-cultural sphere, the consolidated budget of the Russian Federation, Federal budget, municipal services.

JEL Classification: H51, H52, H53, H55. 